\title{
Cucurbitaceae Germplasm Resistance to Verticillium Wilt and Grafting Compatibility with Watermelon
}

\author{
Abigail Attavar \\ Department of Horticulture, Washington State University, Northwestern \\ Washington Research and Extension Center, 16650 State Route 536, Mount \\ Vernon, WA 98273
}

Lydia Tymon

Department of Plant Pathology, Washington State University, Northwestern Washington Research and Extension Center, 16650 State Route 536, Mount Vernon, WA 98273

\section{Penelope Perkins-Veazie \\ Department Horticultural Science, North Carolina State University, Suite 1329, 600 Laureate Way, Kannapolis, NC 28081}

Carol A. Miles

Department of Horticulture, Washington State University, Northwestern Washington Research and Extension Center, 16650 State Route 536, Mount Vernon, WA 98273

Additional index words. crop quality, disease resistance, germplasm accessions, grafting success, soilborne disease, yield

\begin{abstract}
Grafting is used in watermelon [Citrullus lanatus (Thunb.) Matsum and Nakai] production as a means to combat soilborne diseases. To support the development of new rootstock cultivars in the United States, we screened cucurbit germplasm accessions for resistance to verticillium wilt (caused by Verticillium dahliae Kleb.) and for compatibility as watermelon rootstocks. Screening was done using a field naturally infested with $V$. dahliae [5 and 7.5 colony-forming units (cfu) $\cdot \mathrm{g}^{-1}$ soil in 2017 and 2018, respectively], and plants were inoculated at transplanting (1.5 and $104 \mathrm{cfu}$ of $V$. dahliae per plant in 2017 and 2018, respectively). In 2017, 56 germplasm accessions from three genera commonly used as rootstocks, Cucurbita, Lagenaria, and Benincasa, were sourced from the U.S. Department of Agriculture (USDA) National Plant Germplasm System and area under the verticillium wilt (disease) progress curve (AUDPC) values ranged from 16 to 397. The 14 accessions with the lowest AUDPC values and good germination ( $>40 \%)$ were used as rootstocks along with the commercial rootstock cv. Tetsukabuto (control), and all were grafted with watermelon cv. Secretariat as the scion in 2018 . Grafted plant survival rate was greatest for 'Tetsukabuto' $(90 \%)$ and the accession PI 381840 (L. siceraria) $(89 \%)$, and ranged from $22 \%$ to $85 \%$ for all other accessions. All grafted treatments that produced mature fruit in 2018 tended to flower at the same time as nongrafted 'Secretariat', with first male and female flowers occurring in 45 to 50 days and 44 to 51 days after transplanting, respectively. There were no significant differences in AUDPC values due to grafting or when accessions were compared with 'Tetsukabuto'. Only six accessions produced mature fruit when grafted with 'Secretariat', indicating they were compatible for watermelon grafting. Fruit weight and number as well as total soluble solids, $\mathrm{pH}$, lycopene content, rind firmness and thickness, and dry matter content were similar for all accessions and 'Tetsukabuto' grafted on 'Secretariat'. Only fruit flesh firmness differed and was highest for 'Secretariat' grafted on 'PI 491316' and lowest for 'Secretariat' grafted on 'PI 49174'. The six verticillium wilt-tolerant accessions that were compatible with watermelon could potentially be used as rootstocks or as sources of genetic resistance in rootstock breeding programs.
\end{abstract}

Watermelon (Citrullus lanatus) production in the United States has almost doubled since the 1989 Watermelon Research and Promotion Act (United States Code, 2019), and in 2018, about two million metric tons of watermelon were produced, with Florida, Texas, and California being the top-producing states (Economic Research Service, 2013; National Agricultural Statistics Service, 2019).
In Washington State, watermelon is primarily grown in the Columbia River Basin, where current production is estimated at 243 ha (Timothy Waters, personal communication). One of the barriers to increasing watermelon production in this region of southeastern Washington is verticillium wilt (caused by Verticillium dahliae), which can cause rapid vine decline and yield loss. Watermelon does not have resistance to $V$. dahliae (Pscheidt and Ocamb, 2019), and so management tactics are aimed at reducing $V$. dahliae microsclerotia, which serve as the primary inoculum, and include fumigation and crop rotation. However, these controls are not always effective.

Recent studies in Washington have shown that grafting watermelon onto resistant rootstocks is a suitable management option for verticillium wilt (Buller et al., 2013; Dabirian et al., 2017; Wimer et al., 2015a). On a commercial scale, growers in Asia have been using grafting for several decades as a management strategy for biotic stresses such as fusarium wilt and verticillium wilt, and abiotic stresses such as soil salinity and cold stress in watermelon. For example, Japan has used commercial watermelon grafting since 1927 (Tateishi, 1927), and cucurbit rootstocks in Japan have been well researched. In comparison, commercial grafting in the United States began only in the 1990s (Kubota, 2016), which could be the reason that few watermelon rootstocks are available in the domestic market. Most rootstock cultivars are imported into the United States from Asia by seed companies that are involved in breeding these rootstocks, and seeds generally are not sold directly to growers. Currently, the cost of a grafted watermelon seedling can be up to five times greater than that of a nongrafted seedling (Galinato et al., 2016) and can discourage growers from using grafted transplants as a disease management strategy. The cost of labor represents $48 \%$ to $60 \%$ of the total cost of each grafted watermelon seedling (Galinato and Gallardo, 2017; Lewis et al., 2014), and the cost of rootstock seeds can be twice that of watermelon seeds on average, depending on the cultivar and on the number of seeds purchased (Lewis et al., 2014).

The rootstock species that are most commonly used for watermelon grafting are bottle gourd [Lagenaria siceraria (Mol.) Standl.], interspecific hybrids between Cucurbita maxima Duch. and C. moschata Duch., and wild watermelon (Citrullus spp.) (Davis et al., 2008). These rootstocks are used because of their grafting compatibility with watermelon and their resistance to biotic and abiotic stresses. Grafting compatibility can be defined as the successful union of the rootstock and scion in a manner that does not compromise fruit yield and quality. Previous studies have found that yield of watermelon grafted onto interspecific Cucurbita hybrids and $L$. siceraria can be equivalent to or greater than that of nongrafted watermelon (Bekhradi et al., 2011; Paroussi et al., 2007; Wimer et al., 2015a). Yetışır et al. (2003) also reported that watermelon grafted onto $L$. siceraria produced higher yield than Cucurbita hybrids. Use of Benincasa hispida (Thunb.) Cogn. as a rootstock has been attempted in the past, but difficulties regarding seedling emergence have hampered further investigations (Yetışır et al., 2003). In some studies, the screening of cucurbit germplasm for resistances to diseases such as 
powdery mildew (Block and Reitsma, 2005), Zucchini yellow mosaic virus (Ling and Levi, 2007), and fusarium wilt (Huh et al., 2001) has led to the identification of resistant accessions for these diseases. Only a few studies have been carried out for verticillium wilt on cucurbits although identification of accessions with verticillium wilt resistance could be helpful for rootstock development. For example, Wimer et al. (2015b) demonstrated that several germplasm accessions are resistant to verticillium wilt, but their suitability for use as rootstocks was not examined.

The rootstock as well as the scion can affect fruit quality of grafted watermelon. For instance, fruit TSS of 'Sugar Baby' was highest when grafted onto C. maxima $\times C$. moschata, whereas 'Crimson Sweet' fruit had the greatest TSS when grafted onto L. siceraria compared with nongrafted fruit (Petropoulosa et al., 2012). In the same study, fruit from 'Crimson Sweet' grafted onto C. maxima $\times$ C. moschata had greater firmness than those from nongrafted treatments, but total soluble solids (TSS) and lycopene were similar to nongrafted watermelon. In contrast, TSS was reported to be lower on 'Crimson Tide' grafted to C. maxima and C. moschata (Yetışır et al., 2003), and 'Extazy' grafted onto Cucurbita rootstocks also had reduced TSS (Edelstein et al., 2014). Lycopene in seedless watermelon fruit from grafted plants has been found to be greater than from nongrafted plants (Liu et al., 2017). Kyriacou et al. (2015) reported that when compared with nongrafted seeded watermelon, watermelon grafted onto interspecific Cucurbita rootstock had greater lycopene content, and the rootstock accounted for $\approx 45 \%$ of its total variance.

The objective of this study was to identify cucurbit germplasm entries from the USDA NPGS that are resistant to verticillium wilt, compatible for grafting with watermelon, and have a positive impact on fruit quality. The potential outcomes of this study would expand the genetic diversity of rootstocks, reduce seed costs for rootstock, and increase access to rootstock seeds, all of which would aid adoption of vegetable grafting as an

Received for publication 9 Oct. 2019. Accepted for publication 12 Nov. 2019.

Published online 10 January 2020.

Technical assistance provided by Patricia Kreider and Edward Scheenstra, proofreading by Dr. Debra Inglis and Pinki Devi, and funding support provided by U.S. Department of Agriculture National Institute of Food and Agriculture (NIFA) Specialty Crop Research Initiative Grant 2011-51181-30963 and NIFA Hatch Project 1017286 are gratefully acknowledged.

A.A. is an MS Student.

L.T. is a Postdoctoral Researcher.

P.P.-V. is a Professor.

C.A.M. is a Professor and Horticulturist.

L.T. is the corresponding author. E-mail: lydia.tymon@ wsu.edu.

This is an open access article distributed under the CC BY-NC-ND license (https://creativecommons.org/ licenses/by-nc-nd/4.0/). integrated pest management strategy for verticillium wilt.

\section{Materials and Methods}

Experimental site and design. The study was carried out in 2017 and 2018 at Washington State University (WSU) Northwestern Washington Research and Extension Center near Mount Vernon, WA. In 2017, cucurbit germplasm accessions were evaluated for tolerance to $V$. dahliae, and selected accessions were tested as rootstocks for grafted watermelon in 2018. The field site selected for the study was naturally infested with $V$. dahliae and has been used for verticillium wilt research since 2010. The soil is Skagit silt loam, a fine-silty mixed nonacid mesic Typic Fluvaquents, with $6.5 \mathrm{pH}$ and $2.7 \%$ organic matter (USDA, 2019). The field was cover cropped with Austrian winter pea (Pisum sativum ssp. arvense) and chickpea (Cicer arietinum) in the winters of 2016 and 2017 , respectively. Weather data were collected $\approx 0.3 \mathrm{~km}$ from the field site by a WSU AgWeatherNet station.

The study was arranged in a randomized complete block design with three replications both years. In 2017, there were 58 entries, and in 2018, there were 14 entries (Table 1). Plots both years were a single row of six plants spaced $1 \mathrm{~m}$ apart in a raised bed, for a total of 18 plants per entry each year. Beds measured $15 \mathrm{~cm}$ in height, $90 \mathrm{~cm}$ in width, and $2.7 \mathrm{~m}$ from center to center. Due to the wide spacing between beds that provided separation between plots to facilitate disease rating, plant density both years was 3985 plants per hectare, which was less than half the density recommended for commercial watermelon production. The field was fertilized with $110 \mathrm{~kg} \cdot \mathrm{ha}^{-1}$ of nitrogen (N) in 2017 (WilGro Organic Fertilizer 8N-0.87P-3.32K; Wilbur Ellis, Mount Vernon, WA) and $105 \mathrm{~kg} \cdot \mathrm{ha}^{-1}$ of $\mathrm{N}$ in 2018 (Nutririch 8N-0.8P-3.3K; Stutzman Environmental Products, Canby, OR). In 2018, soil analysis indicated that the field was low in sulfur (S), and supplemental S was applied as calcium sulfate (Garden Pearls Gypsum; Columbia River Carbonates, Woodland, WA) on 7 May at the rate of $8 \mathrm{~kg} \cdot \mathrm{ha}^{-1}$ of S. Fertilizer was applied using a drop spreader, then beds were shaped (Rain-Flo 2600; Rain-Flo Irrigation, East Earl, PA) and simultaneously mulched with black plastic film $(25.4 \mu \mathrm{m}$; Filmtech Corp, Allentown, PA) and laid with drip tape (T-Tape model 508-08-340, 20-cm emitter spacing, $250 \mathrm{~L} \cdot \mathrm{ha}^{-1}$; Rivulis, San Diego, CA). During the growing season, plants were irrigated once a week at the rate of $4142 \mathrm{~L} \cdot \mathrm{ha}^{-1}$ on average.

Field soil assay. An assay was carried out both years to quantify the soil populations of $V$. dahliae before and after the study (8 May and 28 Nov., respectively, both years). Each year, from the experimental area of $4115 \mathrm{~m}^{2}$, six soil cores, each measuring $4.5 \mathrm{~cm}$ diameter, were obtained from a depth of $15 \mathrm{~cm}$, using a systematic sampling method in an X pattern. The soil cores were broken into pieces and placed in paper trays and allowed to air dry in a greenhouse for 1 week. Subsequently, $1.5 \mathrm{~g}$ of soil per dried sample were ground using a mortar and pestle, and 1-g subsamples were transferred to saltshakers. Mortars, pestles, and saltshakers were disinfested with $70 \%$ ethanol and allowed to dry before use. Following the method of Butterfield and DeVay (1977), each subsample was equally distributed among 10 plates of NP-10 selective media (Goud and Termorshuizen, 2003). The plates were incubated for 4 weeks at ambient temperature $\left(\approx 25^{\circ} \mathrm{C}\right)$ in the dark. Following the incubation period, plates were gently washed under running tap water to remove soil, and the number of cfu per gram of dry soil was counted using a dissecting microscope at $40 \times$ magnification. Colonies of $V$. dahliae were identified by their morphology, as described by Goud et al. (2003).

Plant material. In 2017, 56 cucurbit accessions were selected from the USDA NPGS and included the four genera and species that are used as watermelon rootstocks: B. hispida (8 accessions), C. maxima (14 accessions), C. moschata (20 accessions), and L. siceraria (14 accessions) (Table 1). Selected accessions originated from regions where $V$. dahliae occurs on major crops and represented a wide geographic diversity (Fig. 1). Experimental controls consisted of two commercial cultivars, rootstock cv. Tetsukabuto (C. maxima $\times$ C. moschata) (American Takii, Inc., Salinas, CA) as the verticillium wilt-resistant control (Wimer et al., 2015a) and diploid (seeded) watermelon cv. Sugar Baby (Osborne Quality Seeds, Mount Vernon, WA) as the verticillium wilt-susceptible control. 'Sugar Baby' was seeded on 5 May, the 56 accessions were seeded on 11 May, and 'Tetsukabuto' was seeded on 18 May. 'Sugar Baby' was seeded earlier than the other accessions because it has a slower growth rate, and 'Tetsukabuto' was seeded later due to late arrival of seed.

In 2018, 14 accessions with AUDPC values not significantly different from 'Tetsukabuto' and that had vigorous plant growth in 2017 and good seed germination $(>40 \%)$ were selected as rootstocks. The 14 accessions that were included in 2018 were from two species, $L$. siceraria (eight accessions) and C. moschata (six accessions), while 'Tetsukabuto' was used as the resistant control. Triploid (seedless) watermelon cv. Secretariat (Sakata Seeds America, Inc., Morgan Hill, CA) was used as both the scion and nongrafted susceptible control; thus, grafting in this study was intergeneric (Pofu et al., 2012). A seedless cultivar was selected for this experiment as farmers in Washington mostly grow triploid cultivars. 'Secretariat' was seeded on 21 May and 'Tetsukabuto', and the 14 accessions were seeded 1 week later on 28 May. The staggered seeding dates were to compensate for the different growth rates of the rootstock and scion and to ensure that plants would be of similar size at the time of grafting.

Grafting and graft survival. The experiment in 2017 did not include grafted plants, whereas in 2018, the experiment included grafted and nongrafted seedlings. However, in 2018, PI 560946 and PI 43849 were not 
Table 1. List of entries, including germplasm genera and species, origin, and source [USDA Plant Genetic Resources Unit (PGRU) and Plant Genetic Resources Conservation Unit (PGRCU)] that were screened for verticillium wilt resistance in 2017 and 2018.

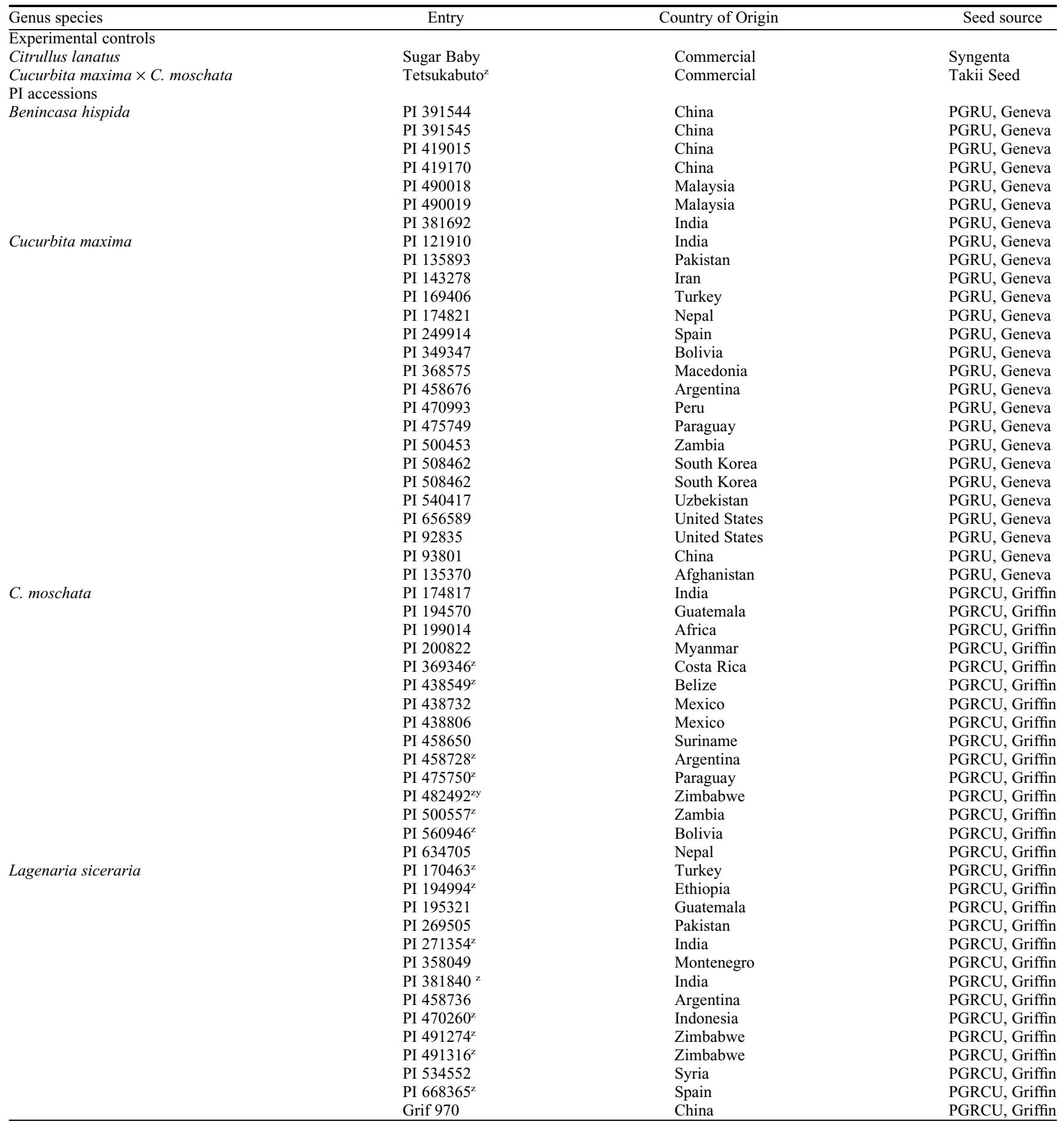

${ }^{\mathrm{z}}$ These accessions were selected for screening in 2018 as rootstocks grafted with 'Secretariat', a seedless watermelon, as the scion.

${ }^{\mathrm{y}}$ This accession was not included in 2018 due to unavailability of seed.

included as nongrafted treatments due to poor germination and consequently insufficient number of plants. Seedlings were grafted on 4 June using the one-cotyledon method, and plants were healed using a protocol developed for grafted watermelon at this experimental site (Miles et al., 2016). Seedlings were placed in a dark, humid healing chamber (Johnson and Miles, 2011) and were gradually reintroduced to light and greenhouse conditions over an 8-d healing period.
Plants were moved to a greenhouse bench for $3 \mathrm{~d}$ and then to an outdoor tunnel for $3 \mathrm{~d}$ for hardening off. Plant survival was recorded 8 , 11,15 , and $21 \mathrm{~d}$ after grafting. Survival of grafted plants was rated visually where plants with wilted scion (up to $50 \%$ of leaves and stems flaccid) were recorded as not successfully grafted; however, these data were only observational because grafting was not replicated.

Inoculum preparation. In both years, a $V$. dahliae sand inoculum was prepared using isolate 'JAW 13-114', which was originally collected from a watermelon host from the same location in 2014 (Wimer et al., 2015b). The $V$. dahliae isolate was cultured on halfstrength potato dextrose agar medium for 2 weeks. A sand inoculum was prepared as described by Wheeler and Johnson (2016). Three 5-mm agar plugs were cultured in 150 $\mathrm{mL}$ of sterile Czapek Dox broth (MP Biomedicals, Solon, OH) on 30 Jan. 2017 and 17 Apr. 2018. The broth was placed on a rotary 

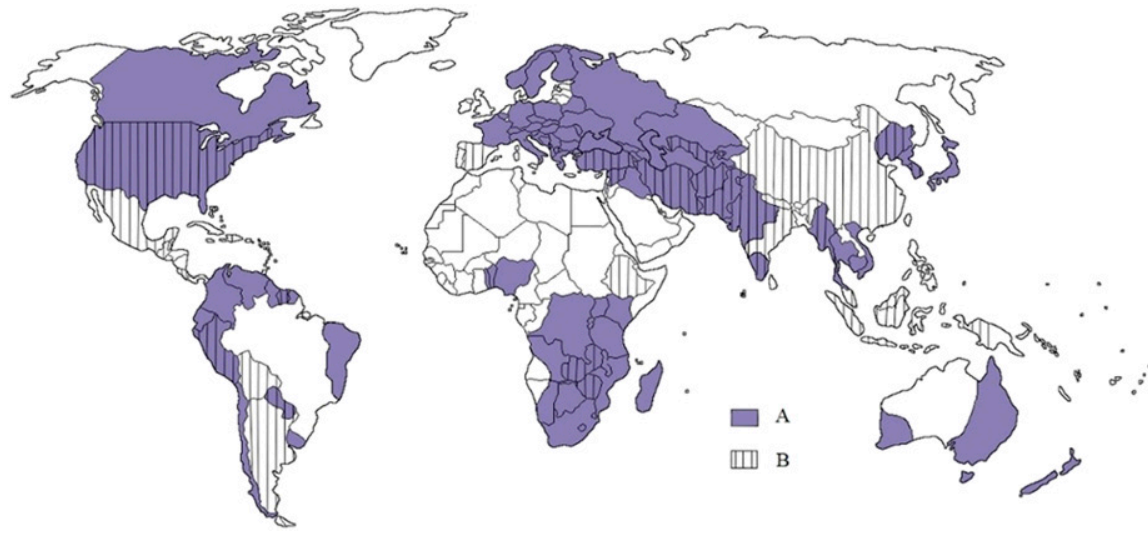

Fig. 1. World map depicting (A) areas where presence of $V$. dahliae is documented, adapted from Pegg (1984) and (B) countries from which Cucurbitaceae germplasm used in this study were collected by the U.S. Department of Agriculture National Plant Germplasm System. Germplasm accessions in this study were evaluated for their resistance to verticillium wilt at Washington State University, Northwestern Washington Research and Extension Center near Mount Vernon, WA, in 2017.

shaker at $150 \mathrm{rpm}$ for $7 \mathrm{~d}$. In a 2 -L conical flask, $700 \mathrm{~mL}$ of sand was autoclaved twice with a 24-h resting period in between. The broth was poured onto the sand in the flask and agitated using aseptic technique in a laminar airflow (LAF) hood. The moist sand was transferred to a previously autoclaved stainless-steel pan lined with two layers of paper towels, one layer of mesh screen, and one layer of Mira cloth (EMD Millipore Corp, Billerica, MA). The pan with the sand then was left in the LAF hood for $5 \mathrm{~d}$, transferred to a chemical fume hood, and allowed to dry for an additional 4 weeks. In 2017, the sand inoculum was stored in plastic jars at room temperature $\left(\approx 25{ }^{\circ} \mathrm{C}\right)$ for 12 weeks before transplanting, whereas in 2018, the sand inoculum was transferred to mushroom grow bags (Unicorn Imp. \& Mfg. Corp., Plano, TX) with a $0.2-\mu \mathrm{m}$ filter to allow for oxygen exchange, before storing at $4{ }^{\circ} \mathrm{C}$ for 3 weeks before transplanting. This difference in storage protocol between the 2 years was due to improved survival of microsclerotia in the sand at $4{ }^{\circ} \mathrm{C}$. The amount of inoculum delivered per plant was estimated each year by placing the sand inoculum in a disinfested salt shaker (to simulate method of inoculation), applying to 10 plates of NP-10 medium, and counting the number of colonies formed per plate after a 4-week incubation period.

Transplanting and inoculation. The plants were inoculated at the time of transplanting, on 1 June 2017 and 20 June 2018. Approximately 1 to $2 \mathrm{~mm}$ of the roots were trimmed with clippers to increase the likelihood of infection by the pathogen. The inoculum was placed in a saltshaker and shaken once over each planting hole in 2017 , delivering $\approx 1.5$ cfu per planting hole. Due to the low cfu counts in 2017, three shakes of sand inoculum were administered in 2018; however, due to the improved survival of microsclerotia in the sand culture, a total of $104 \mathrm{cfu}$ of $V$. dahliae per planting hole was delivered. While transplanting the grafted seedlings in 2018 , care was taken to maintain the graft union $5 \mathrm{~cm}$ above the soil line to prevent adventitious rooting of the scion.

Disease assessment. Disease assessment began on 15 Aug. in 2017 and 14 Sept. in 2018, when the first symptoms of verticillium wilt appeared (i.e., flagging, chlorosis, and necrosis). Thereafter, plants were rated for disease severity on a weekly basis until harvest, which included six ratings in 2017 and four ratings in 2018. Disease severity was assessed as the percent of the canopy displaying symptoms of verticillium wilt. To compare disease development among the treatments during the growing season, area under the disease progress curve values were calculated from the severity ratings (Shaner and Finney, 1977).

Flowering, harvest, and fruit quality. In 2018 , the plants in each plot were scouted in the morning three times a week to detect male and female flowers. The date of the first male and first female flower for each plot was recorded when petals were fully extended and stamens and pistils were visible. Fruit in each plot were monitored for ripeness, as indicated by the browning of the leaflet and tendril at the pedicel that connected the fruit to the vine (Miller et al., 2013). Ripe fruit were harvested on 15 Oct. (117 d after transplanting), and fruit weight and number per plot were recorded. Three representative fruit were randomly selected from each plot to test fruit quality characteristics. Each fruit was quartered from stem to blossom end, and three slices each $1 \mathrm{~cm}$ thick were cut from one-quarter of each fruit. Rind thickness was recorded for one slice by removing the flesh and skin and measuring the thickness of the white rind using a digital caliper (Mitutoyo Corporation, Kanagawa, Japan). Rind firmness and flesh firmness also were measured for the same slice using a penetrometer (Ametek, Hatfield, PA) with tip sizes of $0.5 \mathrm{~mm}$ and $3.5 \mathrm{~mm}$, respectively. Using the same slice, TSS ( ${ }^{\circ}$ Brix) was measured with a handheld refractometer (Palm Abbe PA202; Misco, Solon, $\mathrm{OH}$ ). Three subsamples were measured per slice and the average value per fruit was calculated. From the second slice, $\approx 60 \mathrm{~g}$ of flesh was collected and fresh weight was measured. The flesh was dried in an oven at $60{ }^{\circ} \mathrm{C}$ for $4 \mathrm{~d}$, dry weight was measured, and percent of water was calculated.

Lycopene was measured for the third slice by collecting a sample of $\approx 60 \mathrm{~g}$, and freezing the sample at $-14{ }^{\circ} \mathrm{C}$ until analysis. Frozen samples were placed in a polystyrene foam cooler with ice substitute packs (Blue Ice, Rubbermaid, Atlanta, GA) and shipped via overnight transport to the laboratory at North Carolina State University. On 29 Nov. and 4 Dec., samples were thawed, placed in a vial, and ground using a cell and tissue homogenizer (Geno/Grinder; Spex SamplePrep, Metuchen, NJ). Using a $50-\mathrm{mL}$ disposable tube, $5 \mathrm{~mL}$ of the ground puree and $15 \mathrm{~mL}$ of distilled water were added and shaken until homogenous. The mixture was then placed in a 20-mL glass cuvette and the absorbance (A) recorded at 560 and $700 \mathrm{~nm}$ using a colorimeter (UltraScan PRO Spectrophotometer, Hunter Associate Laboratory Inc., Reston, VA). From the absorbance readings, total lycopene was calculated using the following formula:

$$
\begin{aligned}
\text { Total lycopene }\left(\mu \mathrm{g} \cdot \mathrm{g}^{-1}\right)= & (\mathrm{A} 560-\mathrm{A} 700) \\
& \times 28
\end{aligned}
$$

where A560 and A700 represent absorbance at $560 \mathrm{~nm}$ (lycopene) and $700 \mathrm{~nm}$ (haze), 4 is the dilution factor, and 28 is the slope (Davis et al., 2003).

Statistical analysis. AUDPC and relative AUDPC (rAUDPC) were calculated using the agricolae package in $\mathrm{R}$ (Mendiburu, 2015; Pohlert, 2018; R Core Team, 2013). AUDPC and rAUDPC values in 2017 and 2018 did not satisfy normality assumptions and were analyzed using nonparametric Kruskal-Wallis test. Entries with fewer than two replications were omitted from the analyses. All other data were analyzed using JMP software (Version 14.0.0 for Mac; SAS Institute, Cary, NC). Data for all parameters were tested for normality using ShapiroWilk test. Days to flowering, yield, fruit number, and fruit quality characteristics data conformed to normality assumptions and were analyzed using analysis of variance and means were discriminated using Tukey's honestly significant difference at significance level $P \leq 0.05$.

\section{Results}

Environmental conditions, field soil assay, and disease assessment. Average temperature during the 2017 growing season (1 June to 9 Oct.) was $16^{\circ} \mathrm{C}$, with an average minimum of $10^{\circ} \mathrm{C}$ and average maximum of $22{ }^{\circ} \mathrm{C}$ (AgWeatherNet, 2019). In 2018, the average temperature during the growing season (20 June to 15 Oct.) was $15{ }^{\circ} \mathrm{C}$, and average minimum and maximum temperatures were $9{ }^{\circ} \mathrm{C}$ and $21^{\circ} \mathrm{C}$, respectively. Total precipitation during the growing season was $104 \mathrm{~mm}$ in 2017 and $67 \mathrm{~mm}$ in 2018. 
Table 2. Area under the disease progress curve (AUDPC) and relative AUDPC (rAUDPC) values for commercial cultivar controls and germplasm accessions where there was no grafting in 2017, and in 2018, only selected accessions were included, and rootstock and accessions were all grafted onto 'Secretariat'; this field study was carried out both years at the Northwestern Washington Research and Extension Center near Mount Vernon, WA.

\begin{tabular}{|c|c|c|c|c|c|c|c|}
\hline & \multicolumn{4}{|c|}{ Nongrafted } & \multicolumn{3}{|c|}{2018 AUDPC } \\
\hline & 2017 AUDPC & 2017 rAUDPC & 2018 rAUDPC & $P$ value $^{\mathrm{z}}$ & Nongrafted & Grafted & $P$ value $^{y}$ \\
\hline Sugar Baby or Secretariat & 2,084 & 0.61 & 0.67 & 0.83 & 1,268 & $\mathrm{NA}^{\mathrm{x}}$ & NA \\
\hline Tetsukabuto & 772 & 0.22 & 0.46 & 0.13 & 871 & 904 & 0.82 \\
\hline \multicolumn{8}{|l|}{ Selected accessions } \\
\hline PI 560946 & 385 & 0.11 & $-^{\mathrm{w}}$ & - & - & 1,200 & - \\
\hline PI 170463 & 386 & 0.11 & 0.50 & 0.05 & 954 & 899 & 0.51 \\
\hline PI 475750 & 404 & 0.12 & 0.47 & 0.05 & 896 & 858 & 0.83 \\
\hline PI 438549 & 422 & 0.12 & - & - & - & 1,258 & - \\
\hline PI 194994 & 487 & 0.14 & 0.37 & 0.05 & 704 & 1,053 & 0.28 \\
\hline PI 271354 & 503 & 0.15 & 0.61 & 0.05 & 1,160 & 985 & 0.18 \\
\hline PI 381840 & 538 & 0.16 & 0.63 & 0.05 & 1,193 & 794 & 0.05 \\
\hline PI 369346 & 628 & 0.18 & 0.47 & 0.05 & 886 & 787 & 0.28 \\
\hline PI 491274 & 829 & 0.24 & 0.54 & 0.13 & 1,028 & 813 & 0.28 \\
\hline PI 491316 & 829 & 0.24 & 0.50 & 0.05 & 945 & 949 & 1.0 \\
\hline PI 470260 & 838 & 0.25 & $一^{v}$ & - & - & 1,046 & - \\
\hline PI 500557 & 1,108 & 0.33 & - & - & - & 1,153 & - \\
\hline PI 668365 & 1,151 & 0.34 & 0.49 & 0.51 & 928 & 930 & 0.51 \\
\hline PI 458728 & 1,398 & 0.41 & 0.54 & 0.51 & 1,029 & 788 & 0.18 \\
\hline$P$ value $^{\mathrm{u}}$ & & & & & 0.18 & 0.21 & \\
\hline
\end{tabular}

Remaining accessions

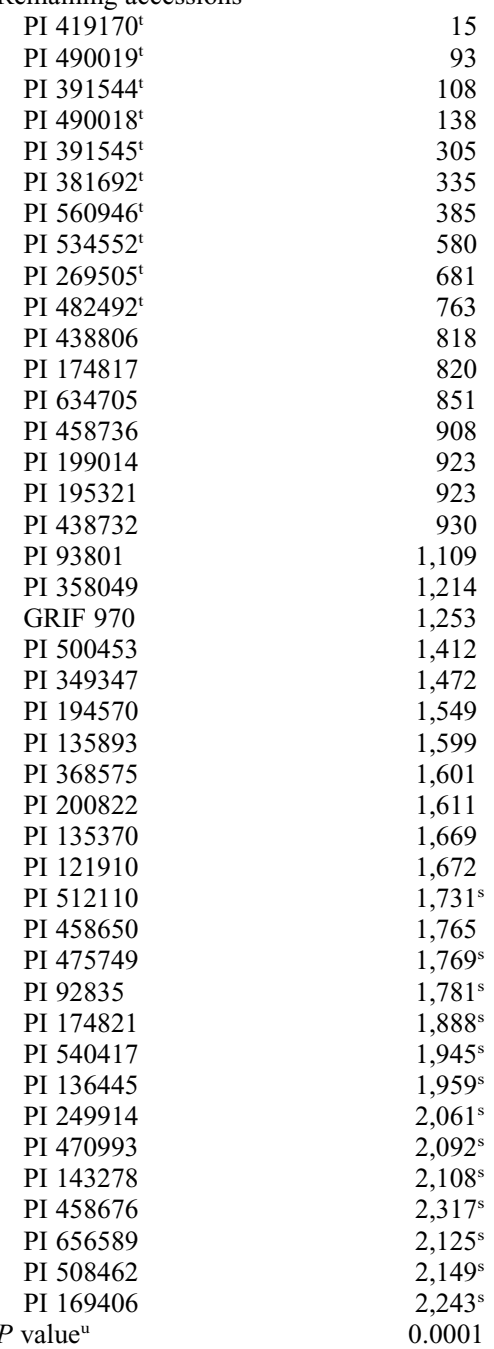

$P$ value ${ }^{\mathrm{u}}$

5

93
108

138

385

580

763

818

908

923

930

1,109

, 253

,412

1,472

1,599

1,601

, 611
, 669

1,672

$1,731^{\mathrm{s}}$

765

$1,888^{\mathrm{s}}$

$2,061^{\mathrm{s}}$

$2,092^{\mathrm{s}}$

$2,108^{\mathrm{s}}$

$2,317^{\mathrm{s}}$ 0.0001

${ }^{\mathrm{z}} P$ values compare rAUDPC values in the same row for 2017 and 2018 for each entry and are considered significant when $P \leq 0.05$.

${ }^{\mathrm{y}} P$ values compares AUDPC values in the same row for nongrafted and grafted entries in 2018 and are considered significant when $P \leq 0.05$.

${ }^{x}$ Watermelon was not self-grafted in this study, hence there is no AUDPC value for grafted 'Secretariat' and no $P$ value for comparing nongrafted and grafted AUDPC values for this entry.

${ }^{\mathrm{w}}$ Nongrafted plants were not included due to poor seed germination and consequent insufficient plant number.

${ }^{\mathrm{v}}$ Plants died from verticillium wilt, precluding AUDPC measurement.

${ }^{\mathrm{u}} P$ values are for AUDPC values in the same column and are considered significant when $P \leq 0.05$.

${ }^{t}$ Although these entries had low AUDPC values, they were not selected for the follow-up experiment because of poor germination $(<40 \%)$.

'AUDPC value is significantly different from 'Tetsukabuto'.

$\mathrm{NA}=$ not applicable. 
In 2017, the soil populations of $V$. dahliae were $5 \mathrm{cfu} \cdot \mathrm{g}^{-1}$ at transplanting and $9.8 \mathrm{cfu} \cdot \mathrm{g}^{-1}$ after harvest. In 2018, the soil populations were $7.5 \mathrm{cfu} \cdot \mathrm{g}^{-1}$ of $V$. dahliae at the time of transplanting and $6.3 \mathrm{cfu} \cdot \mathrm{g}^{-1}$ after harvest. In 2017, AUDPC value of 'Sugar Baby' (2084) was greater than for most other entries. Thirteen accessions (overall average AUDPC value 1135) had an AUDPC value that was significantly greater $(P=0.0001)$ than the resistant control 'Tetsukabuto' (AUDPC value 772) (Table 2). In 2018, no significant differences were observed among or between nongrafted and grafted entries (Table 2), although seven entries had a significantly higher rAUDPC value in 2018 than $2017(P \leq 0.05)$.

Graft survival and plant productivity. All 14 accessions that were grafted with 'Secretariat' in 2018 had graft survival, although this ranged from $22 \%$ for PI 369346 to $89 \%$ for PI 381840 (Table 3). Although graft survival data were not replicated, observations indicated graft survival was greatest for stock cv. Tetsukabuto (90\%), and five accessions had graft survival of $80 \%$ or greater. In 2018, male flowers appeared 54 days after transplanting (DAT) on average for all grafted treatments, and there was no differ'Secretariat' grafted onto commercial root-

ence due to treatment $(P=0.30)$ (Table 3$)$. 'Secretariat' grafted onto 'Tetsukabuto', PI 458728, PI 491274, and nongrafted 'Secretariat' had the earliest appearance of female flowers (45 DAT on average), significantly earlier than 'Secretariat' grafted onto PI 381840, which occurred 75 DAT $(P=0.03)$. Pollination of eight accession-grafted treatments was unsuccessful or the fruit aborted at an early stage, and these plants also appeared stunted. Nongrafted watermelon 'Secretariat' died before the end of the season due to verticillium wilt and thus did not produce fruit. Treatments that did bear fruit are presented in Tables 4 and 5. Fruit weight and fruit number per plant of 'Secretariat' grafted onto accessions were not significantly different from 'Secretariat' grafted onto 'Tetsukabuto' $(P=0.60$ and $P=0.40$, respectively) (Table 4). TSS, pH, lycopene content, rind firmness and thickness, and dry matter percentage of fruit from all treatments were also similar $(P>0.05$ for all) (Tables 4 and 5). Flesh firmness was greatest for 'Secretariat' grafted onto PI $491274(7.8 \mathrm{~N})$ and least for 'Secretariat' grafted onto PI $491316(3.6 \mathrm{~N})$, and all accessions produced flesh firmness similar to that of 'Secretariat' grafted onto 'Tetsukabuto' $(4.9 \mathrm{~N})(P=0.01)$ (Table 5).

Table 3. Graft survival rate (\%) and days after transplanting (DAT) for appearance of first male and female flowers in watermelon cv. Secretariat nongrafted and grafted onto commercial rootstock control

'Tetsukabuto' and germplasm accessions at Washington State University Northwestern Washington Research and Extension Center near Mount Vernon, WA, in 2018.

\begin{tabular}{lccc}
\hline & & \multicolumn{2}{c}{ Appearance of first flower (DAT) } \\
\cline { 2 - 4 } Treatment $^{z}$ & Graft survival $^{\mathrm{y}}(\%)$ & Male flower & Female flower $^{\mathrm{x}}$ \\
\hline Secretariat & NA & 46 & $45 \mathrm{~b}$ \\
S/Tetsukabuto & 90 & 57 & $46 \mathrm{~b}$ \\
S/PI 381840 & 89 & 45 & $75 \mathrm{a}$ \\
S/PI 475750 & 85 & 56 & $48 \mathrm{ab}$ \\
S/PI 170463 & 85 & 66 & $51 \mathrm{ab}$ \\
S/PI 560946 & 83 & 50 & $53 \mathrm{ab}$ \\
S/PI 491316 & 78 & 67 & $51 \mathrm{ab}$ \\
S/PI 500557 & 75 & 48 & $74 \mathrm{ab}$ \\
S/PI 491274 & 70 & 58 & $46 \mathrm{~b}$ \\
S/PI 438549 & 70 & 49 & $61 \mathrm{ab}$ \\
S/PI 458728 & 67 & 47 & $44 \mathrm{~b}$ \\
S/PI 194994 & 65 & 49 & $51 \mathrm{ab}$ \\
S/PI 271354 & 65 & 48 & $57 \mathrm{ab}$ \\
S/PI 668365 & 60 & 65 & $51 \mathrm{ab}$ \\
S/PI 470260 & 50 & 49 & $60 \mathrm{ab}$ \\
S/PI 369346 & 22 & 0.30 & $50 \mathrm{ab}$ \\
$P$ value & - & 0.03 \\
\hline
\end{tabular}

${ }^{\mathrm{z}}$ All grafted plants had watermelon cv. Secretariat $(\mathrm{S})$ as the scion and are denoted as scion/rootstock.

${ }^{\mathrm{y}} P$ values are not provided because grafting was not replicated due to limited availability of seed.

${ }^{\mathrm{x}}$ Means with the same letter within a column are not significantly different at $P<0.05$; means were discriminated using Tukey's honestly significant difference.

$\mathrm{NA}=$ not applicable.

\section{Discussion and Conclusions}

AUDPC values for seven of the 12 accessions that were included both years as nongrafted treatments were higher in 2018 than 2017. The same field was used both years and $V$. dahliae soil population densities were similar both years at transplanting (5 and $7.5 \mathrm{cfu} \cdot \mathrm{g}^{-1}$ of $V$. dahliae in 2017 and 2018 , respectively). The overall increase in disease development was likely due to the increased number of microsclerotia in the inoculum applied in 2018 (104 cfu of $V$. dahliae) than in 2017 ( $1.5 \mathrm{cfu}$ of $V$. dahliae). As expected, other studies have shown that disease incidence and severity increase as inoculum density increases (Berbegal et al., 2007), although threshold values vary by crop. For example, where $19 \mathrm{cfu} \cdot \mathrm{g}^{-1}$ results in $50 \%$ disease incidence for cotton, as few as 3 $\mathrm{cfu} \cdot \mathrm{g}^{-1}$ is the threshold for strawberry. The threshold values for watermelon and their rootstocks are unknown, and it is of note that in this study only five of the 12 nongrafted accessions died by the end of the growing season despite the high inoculum density applied to transplants in 2018 (104 cfu of V. dahliae).

Yield of grafted plants was low compared with previous studies at the same experimental site. Dabirian et al. (2017) reported that when soil populations of $V$. dahliae were 28 $\mathrm{cfu} \cdot \mathrm{g}^{-1}$, grafted plants had an average yield of $11.6 \mathrm{~kg}$ per plant and average number of fruit per plant was 2.1. When the field was infested with $18 \mathrm{cfu} \cdot \mathrm{g}^{-1}$ soil, Wimer et al. (2015a) reported that grafted plants produced an average yield of $9.25 \mathrm{~kg}$ per plant, with an average of 2.5 fruit per plant. In contrast, the average yield per plant in the current study was much lower, at $2.5 \mathrm{~kg}$ per plant, with less than one fruit per plant. This result most likely occurred because inoculations with $V$. dahliae delivered 7 to 14 times more than the soil population levels found in previous studies.

Watermelon grafted onto the accessions had similar fruit quality parameters compared with watermelon grafted onto 'Tetsukabuto'. Although it was not possible to compare quality of grafted vs. nongrafted fruit in our study because nongrafted plants died due to disease pressure, other studies have found that watermelon fruit from plants grafted onto 'Tetsukabuto' had similar quality as fruit from nongrafted plants.

Table 4. Mean fruit weight (kilograms) and number per plant and total soluble solids (TSS), $\mathrm{pH}$, and lycopene ( $\mu \mathrm{g} \cdot \mathrm{g}^{-1}$ ) of watermelon cv. Secretariat grafted onto commercial rootstock control 'Tetsukabuto' and germplasm accessions at Washington State University Northwestern Washington Research and Extension Center near Mount Vernon, WA, in 2018.

\begin{tabular}{|c|c|c|c|c|c|}
\hline Treatment $^{z}$ & Fruit wt (kg) & Fruit number & TSS ( ${ }^{\circ}$ Brix $)$ & $\mathrm{pH}$ & Lycopene $\left(\mu \mathrm{g} \cdot \mathrm{g}^{-1}\right)$ \\
\hline S/PI 369346 & 1.3 & 0.3 & 10.0 & 6.2 & 45.7 \\
\hline S/PI 458728 & 1.7 & 1.3 & 8.6 & 5.7 & 47.6 \\
\hline S/PI 491274 & 1.6 & 0.7 & 9.5 & 5.7 & 48.3 \\
\hline S/PI 491316 & 1.3 & 0.7 & 9.1 & 5.5 & 42.4 \\
\hline$P$ value & 0.60 & 0.40 & 0.45 & 0.52 & 0.08 \\
\hline
\end{tabular}

${ }^{\mathrm{z}}$ All grafted plants had watermelon cv. Secretariat (S) as the scion and are denoted as scion/rootstock. 
Table 5. Flesh firmness, rind firmness and thickness, and percent dry matter of watermelon cv. Secretariat grafted onto commercial rootstock control 'Tetsukabuto' and germplasm accessions at Washington State University Northwestern Washington Research and Extension Center near Mount Vernon, WA, in 2018.

\begin{tabular}{lcccc}
\hline Treatment $^{z}$ & Flesh firmness $(\mathrm{N})^{\mathrm{y}}$ & Rind firmness $(\mathrm{N})$ & Rind thickness $(\mathrm{mm})$ & Dry matter $(\%)$ \\
\hline S/Tetsukabuto & $4.9 \mathrm{ab}$ & 24.6 & 23 & 29.7 \\
S/PI 194994 & $5.5 \mathrm{ab}$ & 13.9 & 24 & 31.0 \\
S/PI 369346 & $4.7 \mathrm{ab}$ & 22.9 & 24 & 23.8 \\
$\mathrm{~S} /$ PI 458728 & $4.2 \mathrm{ab}$ & 22.5 & 21 & 25.8 \\
$\mathrm{~S} /$ PI 475750 & $6.5 \mathrm{ab}$ & 19.0 & 15 & 21.4 \\
S/PI 491274 & $3.6 \mathrm{~b}$ & 23.7 & 17 & 31.0 \\
S/PI 491316 & $7.8 \mathrm{a}$ & 17.5 & 17 & 31.3 \\
$P$ value & 0.01 & 0.90 & 0.06 & 0.10 \\
\hline
\end{tabular}

${ }^{\mathrm{z}}$ All grafted plants have watermelon cv. Secretariat $(\mathrm{S})$ as scion and are denoted as scion/rootstock.

${ }^{\mathrm{y}}$ Means with the same letter within a column are not significantly different at $P<0.05$, and means were discriminated using Tukey's honestly significant difference.

For example, previous studies at our location where plants were also affected by $V$. dahliae found TSS and lycopene were similar for nongrafted 'TriX Palomar' and 'TriX Palomar' grafted with 'Super Shintosa', 'Just', and 'Tetsukabuto' (Dabirian et al., 2017), and for nongrafted 'Sugar Baby' and 'Sugar Baby' grafted on 'Marvel', 'Rampart', 'Tetsukabuto', and 'Titan' (Wimer et al., 2015a). Only fruit firmness differed significantly among grafted treatments in our current study, which was also similar to results of both Dabirian et al. (2017) and Wimer et al. (2015a). These fruit quality results are also similar to those from Alexopoulos et al. (2007), who found no significant difference in rind thickness and TSS between fruit from grafted and nongrafted plants when there was no disease pressure. In the current study, the two L. siceraria accessions produced fruit with the highest and lowest fruit firmness, suggesting that fruit quality effects may vary for different rootstocks within this species. The death of 'Secretariat' plants before fruit formation precluded a comparison of the yield and fruit quality of grafted plants with the nongrafted control.

Grafting success of accessions in the current study ranged from $22 \%$ to $85 \%$, which was less than grafting success for 'Tetsukabuto' $(90 \%)$. The low survival rate of some accession-grafted watermelon, the abortion of flowers and fruit, and plant stunting were likely due to graft incompatibility, that is, the inability of the rootstock and scion to form a successful graft union. During the healing of the graft union, callus formation joins the two plants together, and the differentiation of the callus leads to formation of xylem and phloem tissues (Melnyk, 2017). Graft incompatibility usually exhibits itself during the early healing period of grafted plants; Martínez-Ballesta et al. (2010), however, reported that incompatibility can be observed as late as the fruiting stage. In the current study, the improper formation of new vascular tissues at the graft union could have led to malnutrition of the plants and could also have caused a shortage of essential elements needed for successful plant pathogen defense (Huber, 1980). This potential inability of a grafted plant to mount defenses could have made the plants more susceptible to verticillium wilt. In the current study, resistance to $V$. dahliae varied considerably within a given accession, and different phenotypes such as leaf type were also observed within each accession, indicating that accession populations were segregating. $\mathrm{Fu}$ ture studies with selected resistant accessions should include homogenizing plant populations before screening for grafting compatibility with watermelon and testing for disease resistance, so that results can be more reliable.

In conclusion, grafting resulted in fruit yield of 'Secretariat' under relatively high levels of disease pressure, indicating that grafting can be used as an effective management strategy for verticillium wilt. Of the 56 accessions evaluated in this study, six performed comparably to commercial rootstock 'Tetsukabuto' with regard to compatibility as rootstocks for watermelon grafting, tolerance to $V$. dahliae, and impact on fruit quality. However, their graft survival ranged from $22 \%$ to $89 \%$. Given the performance of these six accessions under exceptionally high disease pressure, further study is warranted to determine whether they are suitable as watermelon rootstocks or as genetic sources of verticillium wilt resistance in domestic rootstock breeding programs.

\section{Literature Cited}

AgWeatherNet. 2019. The Washington agricultural weather network: Monthly weather data. Washington State Univ. 4 Feb. 2019. <https:// weather.wsu.edu/?p=93150>.

Alexopoulos, A.A., A. Kondylis, and H.C. Passam. 2007. Fruit yield and quality of watermelon in relation to grafting. J. Food Agr. Environ. 5:178-179.

Bekhradi, F., A. Kashi, and M. Delshad. 2011 Effect of three cucurbits rootstocks on vegetative and yield of 'Charleston Gray' watermelon. Intl. J. Plant Prod. 5(2):105-110.

Berbegal, M., A. Ortega, J. García-Jiménez, and J. Armengol. 2007. Inoculum density-disease development relationship in verticillium wilt of artichoke caused by Verticillium dahliae. Plant Dis. 91:1131-1136.

Block, C.C. and K.R. Reitsma. 2005. Powdery mildew resistance in the US national plant germplasm system cucumber collection. HortScience 40:416-420.

Butterfield, E.J. and J.E. De Vay. 1977. Reassessment of soil assays for Verticillium dahliae. Phytopathology 67:1073-1078.
Buller, S., D. Inglis, and C. Miles. 2013. Plant growth, fruit yield and quality, and tolerance to verticillium wilt of grafted watermelon and tomato in field production in the Pacific Northwest. HortScience 48:1003-1009.

Dabirian, S., D. Inglis, and C.A. Miles. 2017. Grafting watermelon and using plastic mulch to control verticillium wilt caused by Verticillium dahliae in Washington. HortScience 52:349-356.

Davis, A.R., W. Fish, and P. Perkins-Veazie. 2003. A rapid hexane-free method for analyzing lycopene content in watermelon. J. Food Sci. 68:328-332.

Davis, A.R., P. Perkins-Veazie, Y. Sakata, S López-Galarza, J.V. Maroto, S.G. Lee, Y.C. Huh, Z. Sun, A. Miguel, S.R. King, and R. Cohen. 2008. Cucurbit grafting. Crit. Rev. Plant Sci. 27:50-74.

Economic Research Service. 2013. United States Department of Agriculture. U.S. Watermelon Ind. 21 Mar. 2019. <https://usda.library.cornell. edu/concern/publications/zw12z528p?locale= en>.

Edelstein, M., J. Tyutyunik, E. Fallik, A. Meir, Y. Tadmor, and R. Cohen. 2014. Horticultural evaluation of exotic watermelon germplasm as potential rootstocks. Scientia Hort. 165:196202.

Galinato, S.P., C.A. Miles, and J.A. Wimer. 2016 Non-grafted and grafted seedless watermelon transplants: Comparative economic feasibility analysis. Washington State Univ. Ext. Pub. TB08.

Galinato, S.P. and R.K. Gallardo. 2017. Cost analysis for vegetable grafting. In: C. Kubota, C. Miles, and X. Zhao (eds.). Chapter 6, Grafting Manual: How to produce grafted vegetable plants. 10 Feb. 2019. < http://www.vegetablegrafting. org/wp/wpcontent/uploads/2018/05/CostAnalysis622-17.pdf $>$.

Goud, J.C. and A.J. Termorshuizen. 2003. Quality of methods to quantify microsclerotia of Verticillium dahliae in soil. Eur. J. Plant Pathol. 109:523-534.

Goud, J.C., A.J. Termorshuizen, and W. Gams. 2003. Morphology of Verticillium dahliae and $V$. tricorpus on semi-selective media used for the detection of $V$. dahliae in soil. Mycol. Res. 107:822-830.

Huber, D.M. 1980. The role of mineral nutrition in defense, p. 381-406. In: J.G. Horsefall and E.B. Cowling (eds.). Plant disease: An advanced treatise: How plants defend themselves. Academic Press, New York.

Huh, Y.C., Y.H. Om, and J.M. Lee. 2001. Utilization of Citrullus germplasm with resistance to fusarium wilt (Fusarium oxysporum f. sp. niveum) for watermelon rootstocks. Proc. II Intl. Symp. Cucurbits 588:127-132.

Johnson, S.J. and C.A. Miles. 2011. Effect of healing chamber design on the survival of grafted eggplant, tomato, and watermelon. HortTechnology 21:752-758.

Kubota, C. 2016. History of grafting, chap. 1. In: C. Kubota, C. Miles, and X. Zhao (eds.). Grafting manual: How to produce grafted vegetable plants. 6 Mar. 2019. <http://www.vegetablegrafting. org/resources/grafting-manual/>.

Kyriacou, M.C., G.A. Soteriou, Y. Rouphael, A.S Siomos, and D. Gerasopoulos. 2015. Configuration of watermelon fruit quality in response to rootstock-mediated harvest maturity and postharvest storage. J. Sci. Food Agr. 96:24002409.

Lewis, M., C. Kubota, R. Tronstad, and Y.J. Son. 2014. Scenario-based cost analysis for vegetable grafting nurseries of different technologies and sizes. HortScience 49:917-930. 
Ling, K.S. and A. Levi. 2007. Sources of resistance to Zucchini yellow mosaic virus in Lagenaria siceraria germplasm. HortScience 42:1124-1126.

Liu, Q., X. Zhao, J.K. Brecht, C.A. Sims, T. Sanchez, and N.S. Dufault. 2017. Fruit quality of seedless watermelon grafted onto squash rootstocks under different production systems. J. Sci. Food Agr. 97:4704-4711.

Martínez-Ballesta, M.C., C. Alcaraz-López, B. Muries, C. Mota-Cadenas, and M. Carvajal. 2010. Physiological aspects of rootstock-scion interactions. Scientia Hort. 127:112-118.

Melnyk, C.W. 2017. Plant grafting: Insights into tissue regeneration. Regeneration 4:3-14.

Mendiburu, F.D. 2015. Agricolae: Statistical procedures for agricultural research. R Package Version 1.2-3.

Miles, C., L. Hesnault, S. Johnson, P. Kreider, and S. Dabirian. 2016. Vegetable grafting: Watermelon. Washington State Univ. Ext. Pub. FS100E. 15 Sept. 2019. < http://cru.cahe.wsu.edu/ CEPublications/FS100E/FS100E.pdf>.

Miller, G., A. Khalilian, J.W. Adelberg, H.J. Farahani, R.L. Hassell, and C.E. Wells. 2013. Grafted watermelon root length density and distribution under different soil moisture treatments. HortScience 48:1021-1026.

National Agricultural Statistics Service. 2019. United States Department of Agriculture. Vegetables Summary 2018. 21 Mar. 2019. $<$ https://usda.library.cornell.edu/concern/publications/ $02870 \mathrm{v} 86 \mathrm{p}$ ?locale $=\mathrm{en}>$.
Paroussi, G., F. Bletsos, G.A. Bardas, J.A. Kouvelos, and A. Klonari. 2007. Control of fusarium and verticillium wilt of watermelon by grafting and its effect on fruit yield and quality. Proc. III Balkan Symp. Vegetables Potatoes 729:281285.

Pegg, G.F. 1984. The impact of Verticillium diseases in agriculture. Phytopathologia Mediterranea 23(2/3):176-192.

Petropoulosa, S.A., E.M. Khahb, and H.C. Passamc. 2012. Evaluation of rootstocks for watermelon grafting with reference to plant development, yield and fruit quality. Intl. J. Plant Prod. 6:1735-6814.

Pofu, K.M., P.W. Mashela, and H. Shimelis. 2012. Inter-generic grafting in watermelon for managing Meloidogyne species: A review. Sci. Res. Essays 7(2):107-113.

Pohlert, T. 2018. PMCMRplus: Calculate pairwise multiple comparisons of mean rank sums extended. $\mathrm{R}$ package version 1.4.1.

Pscheidt, J.W. and C.M. Ocamb. 2019. Watermelon (Citrullus spp.) verticillium wilt. PNW Dis. Mgt. Handbook. Oregon State Univ. 7 Aug 2019. <https://pnwhandbooks.org/plantdisease/ host-disease/watermelon-citrullus-sp-verticilliumwilt>.

R Core Team. 2013. R: A language and environment for statistical computing. R Foundation for Statistical Computing, Vienna, Austria. $<$ http://www.R-project.org $>$.
Shaner, G. and R.E. Finney. 1977. The effect of nitrogen fertilization on the expression of slowmildewing resistance in Knox wheat. Phytopathology 67:1051-1056.

Tateishi, K. 1927. Grafting watermelon onto pumpkin. J. Jpn. Hort. 39:5-8.

United States Code. 2019. Office of Law Revision Counsel, Title 7. Ch. 80: Watermelon Research and Promotion Act. 20 Mar. 2019. <http:// uscode.house.gov/view.xhtml?path=/prelim@ title $/$ chapter80\&edition $=$ prelim $>$.

U.S. Department of Agriculture. 2019. Web soil survey. 3 Oct. 2019. <https://websoilsurvey.sc. egov.usda.gov>.

Wheeler, D.L. and D.A. Johnson. 2016. Verticillium dahliae infects, alters plant biomass, and produces inoculum on rotation crops. Phytopathology 106:602-613.

Wimer, J., D. Inglis, and C. Miles. 2015a. Evaluating grafted watermelon for verticillium wilt severity, yield, and fruit quality in Washington State. HortScience 50:1332-1337.

Wimer, J., D. Inglis, and C. Miles. 2015b. Field and greenhouse evaluations of cucurbit rootstocks to improve verticillium resistance for grafted watermelon. HortScience 50:16251630.

Yetışır, H., N. Sari, and S. Yücel. 2003. Rootstock resistance to fusarium wilt and effect on watermelon fruit yield and quality. Phytoparasitica 31:163-169. 